\title{
A view from the middle of the totem pole
}

\author{
Aarjan Peter Snoek, MBChB
}

Received: 27 May 2015/Accepted: 9 July 2015/Published online: 31 July 2015

(c) Canadian Anesthesiologists' Society 2015

\section{To the Editor,}

As a final-year resident, I read with interest the article ${ }^{1}$ regarding residents' reluctance to challenge authority. There are three points worth stating. First, the scenario contains competing ethical principles. Residents' degree of comprehension of patient autonomy in Jehovah's Witness cases was not explored, and it is conceivable that many residents may not yet have practically encountered this situation. Though abstract conceptualization may have occurred, absence of active experimentation or concrete experience $^{2}$ may have clouded the results. Respect for autonomy certainly should trump beneficence, but in this setting, an intervening action by the resident (stopping the consultant anesthesiologist) causes a maleficent outcome (patient death). The trolley problem, ${ }^{3}$ a thought experiment in ethics, illustrates similar such challenges with scenarios of moral choice. We thus cannot necessarily extrapolate these findings to situations that lack ethical conflict, where the consultant anesthesiologist might imminently cause obvious harm to a patient. As an example, such a scenario would arise if a consultant anesthesiologist were to allow an obstetrician to continue surgery on a woman undergoing Cesarean delivery with inadequate regional anesthesia and consequential pain. In a more clear-cut example, would residents have acted differently in challenging authority?

Second, the residents were initially briefed that they would be evaluated on teamwork. Aspects of teamwork

This letter is accompanied by a reply. Please see Can J Anesth 2015; 62: this issue.

A. P. Snoek, MBChB ( $\square)$

Barts and the London School of Anaesthesia, The Royal London Hospital, London, United Kingdom

e-mail: snoek@doctors.net.uk include collaborating with colleagues and treating them fairly and with respect. ${ }^{4}$ It is conceivable that this introductory remark may have influenced residents' subsequent behaviour by either discouraging them from being forthright or instilling a fear of being labelled "not a team player". Did the mandate influence their resolve to be accommodating or cooperative with the rest of the team come what may? If so, a degree of coercion does partially invalidate the resident challenge findings.

Third, questions 8 to 10 of the interview protocol dealt specifically with hierarchy and comprised a significant portion of the dialogue. The presence of power gradients was implicit in the questioning, and therefore, informal fallacy ${ }^{5}$ potentially impacts the conclusions regarding hierarchy. Perhaps the focus on these assumed power gradients immediately following an emotional simulation experience prompted participants to turn to pecking order as a scapegoat for their inadequate management. Concerning the lack of difference in the modified Advocacy Inquiry Scale scores between the hierarchical and non-hierarchical groups, perhaps deep-seated hierarchy does exist, but it is also possible that factors other than hierarchy, which were not specifically targeted in the interview protocol, may have influenced challenge strength. Pessimistic views of hierarchy may be overrepresented by the combination of a negative simulation experience and the questioning technique employed.

A survey could have been used as an alternative method to explore residents' opinions of hierarchy, thus avoiding simulation with resident deception. Such a simple method could have targeted a larger number of residents, and statements with Likert scales of agreement could have provided a time-efficient technique to quantify residents' views on a number of subjects alluding to power structures. 
Funding No funding was received for this submitted work

Conflicts of interest None declared.

\section{References}

1. Bould MD, Sutherland S, Sydor DT, Naik V, Friedman Z. Residents' reluctance to challenge negative hierarchy in the operating room: a qualitative study. Can J Anesth 2015; 62: 576-86.
2. Kolb DA. The Learning Style Inventory: Technical Manual. Boston: McBer and Company; 1976.

3. Foot $P$. The problem of abortion and the doctrine of the double effect. In: Virtues and Vices. Oxford: Basil Blackwell; 1978.

4. General Medical Council. Good Medical Practice - 25 March 2013. Available from URL: http://www.gmc-uk.org/static/documents/ content/Good_medical_practice_-_English_0914.pdf (accessed June 2015).

5. Kelly D. The Art of Reasoning: With Symbolic Logic. WW Norton \& Company, Inc.; 1994. 